\title{
Techniques for building trust as a factor of psychological security of a person
}

\author{
Tatiana Skripkina ${ }^{1, *}$, Angelica Polina $^{2}$, Elena Ovcharova ${ }^{2}$ \\ ${ }^{1}$ Russian State University for the Humanities, Russia \\ ${ }^{2}$ Volzhsky branch of Volgograd State University, Russia
}

\begin{abstract}
Purpose of the study: The scientific objective of the study is to study the problem of building trust as the basis of psychological security of a person, to develop a model of "the formation of trusting relationships as the basis of psychological security of a person" and define its components. Research methods: ascertaining and formative experiment, questionnaires, testing, method of content analysis of essays, methods of mathematical statistics, Student's t-test and Wilcoxon's t-test. Methods that determine the characteristics of trust in oneself and in others were used, as well as methods that diagnose the psychological safety of the personality of adolescents. The paper examines the theoretical aspects of psychological security of a person in domestic and foreign psychology; concepts that reflect the role of trust and trusting relationships of a person in social interaction and personality development; the concept of deprivation symptoms and modern studies on the problem of raising children and adolescents in a difficult life situation. Research results. The paper presents the results of a study of the peculiarities of the emotional and personal development of adolescents who find themselves in a difficult life situation, which are manifested in a low level of confidence in themselves and in the world, the severity of aggressive reactions and high anxiety. Based on the results of the empirical study, technologies for the formation of trust and psychological safety of a person have been developed, which are the author's model of "the formation of trusting relationships as the basis of psychological security of a person" and a complex of psychocorrectional measures. As components of the psychological security of a person, the following are distinguished: affective-personal, cognitive, behavioral and value-semantic components. Key findings and their significance. Comparative analysis of the obtained results of the empirical study of the experimental and control groups made it possible to confirm the reliability of the identified components of psychological security and the criteria of trust/distrust in the author's model. An innovative approach is defined, in which confidence in oneself and in the world is highlighted as a significant factor of psychological security of a person for the first time. The introduction of a psychocorrectional program made it possible to optimize trusting relationships among adolescents.
\end{abstract}

\section{Introduction}

\footnotetext{
*Corresponding author: skripkinaurao@mail.ru
} 
The study of the phenomenon of trust and the development of technologies for its formation as a factor of psychological security is an important research task, since in Russia, there is an increase in the number of children and adolescents who find themselves in a difficult life situation in connection with life in unfavorable living conditions.

In this category, we included adolescents who are brought up in dysfunctional families, as well as in closed institutions, adolescents left without parental care, adolescents who have been subjected to physical, psychological and emotional abuse. According to the official data of the State Statistics Service in Russia, there are 73 thousand children and adolescents left without parental care and brought up in closed institutions [1].

In adolescents belonging to this category, the need for safety is not satisfied, and an adequate perception of the surrounding world is disturbed. Here the problem is not about safety in general, but about psychological security, without which the personality of a teenager cannot develop harmoniously [2].

Studies have shown that not providing timely assistance to deprived adolescents who find themselves in difficult life conditions leads to profound personal deformations (high aggression, depression, cruelty, affective outbursts, conflict), which often leads to inappropriate behavior, from which the adolescent himself and people around him suffer [3, 4].

According to the approach we are developing, in adolescents of this category, trusting relationships (trust in themselves and in the world, other people) are formed either inadequately, or are not formed at all due to the presence of a syndrome of mental deprivation, which leads to violations of the psychological safety of the individual. We called this phenomenon trust deprivation [2].

Psychological studies prove that a person's social behavior in difficult life situations is determined by a system of trusting relationships, and trust in the world is associated with a sense of security, personal identity, stability and integrity of the individual [5]. In deprived adolescents with a violation of the satisfaction of the need for psychological security, there is an increase in aggressive tendencies, manifestation of cruelty, disregard for the norms of behavior, indifference to significant life events [6].

The aim of this study is to study the problem of the formation of trust as the basis of psychological security of a teenager's personality in a difficult life situation. Psychological security of the personality of an adolescent developing in favorable social conditions that allow satisfying basic natural and, in particular, social needs, an adequate perception of life, an adequate picture of the world associated with the present and the future are formed, which allows them to successfully adapt in society [7].

O. Yu. Zotova [8], T.O. Archakova [8], A.N. Veraksa [8] consider personal safety as a socio-psychological phenomenon and suggest including in its structure such components as cognitive, motivational-need, motivational-evaluative, behavioral, communicative, valuesemantic ones. The authors define psychological security as the inadmissibility of infringement on self-esteem and personal status. The need for security includes the need for stability, predictability of events, as well as the freedom of the individual from external and internal threats [8]. The problem of psychological security of a person is studied in the works of such foreign authors as A. Bandura, A. Edmundson, S. Kimberly, K. Ryff [9], T.K.A. Hunt, [10], K.S Slack, [10], L.M. Berger [10]. Under "psychological security", scholars mean a subjective self-awareness of the integrity and meaningfulness of an individual's being.

In the process of theoretical analysis, the conditions of life and the peculiarities of the formation of the personality of an adolescent in difficult living conditions (pupils of orphanages, boarding schools), which is equated to the conditions of mental deprivation, have been studied $[3,4,11,12,13,14]$. Within the framework of this problem, the approaches of foreign concepts of deprivation symptomatology have been analyzed (J. Bowlby, R. Sears, G. Sullivan, R. Spitz, A. Freud, I. Langmeyer, Z. Mateichik, M. Gardner [11], H. Thomas [ 
11], JR McTavish [12], A. Gonzalez [12], J.M. Warmingham [13], F.A. Rogosch [13], D. Cicchetti [13], J. Coleman [14], J.I. Herzog [15], A.N. Almas [16] and others). Also, modern domestic studies of the problem of raising children and adolescents in closed institutions are considered (I.V. Dubrovina, E.O. Smirnova, A.M. Prikhozhan, N.N. Tolstykh, M.V. Danilova [1], V. N. Oslon [3], M.V. Ermolaeva [17], Smirnova O.V. [17], L.A. Golovey [18] and others).

In our study, trust in oneself and in the world is identified as a basic factor that affects all components of the structure of a person's psychological safety. From the point of view of authoritative authors (K. Horney, E. Erickson, P.N. Shikhirev, etc.), social trust is a pivotal element of the social and psychological well-being of an individual in society. At the same time, there are very few works specifically devoted to the study of the role of trust deprivation in the mental development of a child. In the majority of psychological studies on this issue, it is emphasized that trust is the basis of psychological well-being in a person's life and is a pivotal element that determines reliable ways of interaction between a person and society.

A great contribution to the study of the phenomenon of trust in Russian psychology was made by T.P. Skripkina, who presents trust as a system-forming function in the interaction of a person with the world, which plays a major role in the formation of psychological security. The author identifies trust in the world and trust in oneself as structural elements of trust, therefore, the basic conditions for the emergence of trust are feelings of security and safety, and the frustration of the need for attachment is associated with a lack of basic trust [5].

Among foreign authors (J. Rotter, T. Yamagishi, K.S. Cook, D. Gambetta, K. Jones), there is no single point of view on the nature of this phenomenon. However, the most widespread idea, which became classical in foreign psychology, was about that interpersonal trust is a kind of risky expectation that the other will not use this trust and can be relied on. Among the more modern works are the works of E. Uslaner, K. Jones and K. Haley [19].

We also note that scientists R. Levitsky and B. Bunker built a certain model of trust, in which they identified three main phases of trust: 1) trust based on benefits "This person does what he promised"; "I heard about his good reputation"); 2) trust based on knowledge ("I have sufficient experience of interacting with this person"; "It seems to me that I know this person well"); 3) trust based on identity ("We have common interests and values with him") [20]. This model is the most popular in both foreign and Russian psychology.

\section{Materials and methods}

As the main empirical research methods, the ascertaining and formative experiment were chosen, as well as overt observation, questioning, testing, analysis of the products of activity, conversation, and the method of content analysis of essays.

In order to study trust and the components of psychological security, as well as to identify mental deprivation, deprivation of trust, a comprehensive psychodiagnostic study of adolescents who find themselves in a difficult life situation was carried out. An empirical study was also carried out with adolescents brought up in favorable social conditions (control group).

In total, 180 adolescents aged 14-16 years participated in the empirical part, of which the experimental group included 87 adolescents brought up in deprivation conditions (SPI SS "Volzhsky social rehabilitation center for minors", SSPI SS "Volzhsky center for helping children who have remained without parental care", SP EI "Sredneakhtubinskaya boarding school”), and the control group consisted of 93 adolescents (MBGEU school № 35, MBGEU school № 19).

The developed model of "the formation of trusting relationships as the basis of psychological security of a person" (Fig. 1) made it possible to form the author's complex of 
psychodiagnostic techniques, which were adapted to age characteristics and to the peculiarities of mental development of adolescents who find themselves in difficult life situations.

The following methods were used in the study: the projective method "House-Tree-Man" by J. Buk (modified by R.F. Bieliauskaitè) [2]; methodology "Assessment of selfconfidence" by T.P. Skripkina [21]; a questionnaire for measuring aggressive and hostile reactions by A. Bass and A. Darka (adaptation by A.K. Osnitsky) [22]; method of "Acceptance of others" according to the Feuillet scale [23].

To diagnose the psychological security/violation of the security of adolescents, the content of the components identified in the author's model was studied: communicative competence, socio-psychological adaptation, self-acceptance. For this purpose, the following methods were used: "Diagnostics of social and psychological adaptation" by K. Rogers, R. Diamond [24]; the scale of reactive and personal anxiety according to the Spielberg-Khanin method [25]; L. Michelson's test of communicative skills (adaptation by Yu. Z. Gilbukh) [26]; method of communicative control by M. Schneider [26]. To identify the statistical significance between the indicators of the two groups of adolescents, the methods of mathematical statistics were used: Student's t-test and Wilcoxon's t-test.

As a result of empirical study, a group of deprived adolescents with impaired psychological security was identified in order to conduct psychocorrectional measures aimed at the formation of trusting relationships and psychological safety of adolescents. This group included adolescents who are brought up in dysfunctional families and closed institutions, adolescents left without parental care, as well as adolescents who have been subjected to physical, psychological and emotional abuse.

\section{Results}

The performed theoretical analysis made it possible to single out the technologies of building trust. A set of psychocorrectional measures for adolescents who find themselves in a difficult life situation, developed on the basis of the author's model of the formation of trusting relationships, was used as a technology for building trust as the basis of psychological security of a person (Fig. 1). This technique is aimed at the formation of adequate forms and models of behavior, attitudes towards trust in oneself and in the world, a decrease in personal anxiety and feelings of insecurity in adolescents under conditions of developmental deprivation.

As a result of the theoretical analysis, an innovative approach was determined, in which, confidence in oneself and in the world was highlighted as a significant factor of the psychological security of a person for the first time.

In the model of "the formation of trust relations as the basis of psychological security of a person" (Fig. 1), the criteria for the formation of trust and the criteria for the deprivation of trust are highlighted. As components of the psychological security of a person "presence/violation", the following are distinguished: affective-personal, cognitive, behavioral and value-semantic ones.

Comparative analysis of the obtained results of the empirical study of the experimental and control groups made it possible to confirm the reliability of the identified components of psychological security and the criteria of trust/distrust in the author's model. 


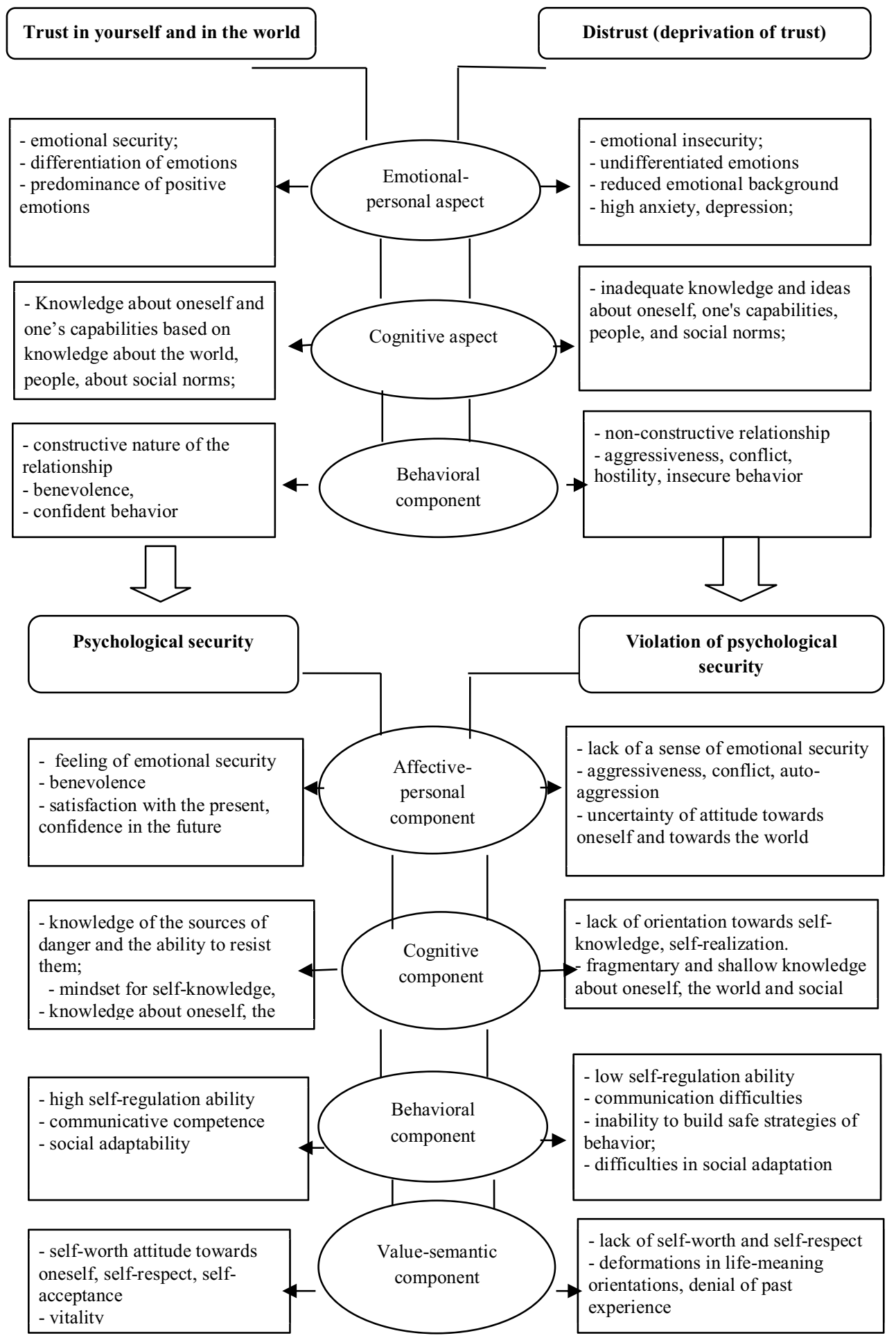

Fig. 1. Model of the building trusting relationships as the basis of psychological security of a person. 
The obtained results of the psychodiagnostic study were confirmed by the statistical significance of the differences using the Student's t-test:

- comparative results according to J. Buck's "House-Tree-Man" method showed that adolescents with impaired confidence building have such symptom complexes as: anxiety $\left(\mathrm{t}_{\text {emp }}=3.9\right.$ at $\left.\mathrm{p}<0.01\right)$, hostility $\left(\mathrm{t}_{\mathrm{emp}}=3.4\right.$ with $\left.\mathrm{p}<0.01\right)$, conflict $\left(\mathrm{t}_{\mathrm{emp}}=5.4\right.$ with $\left.\mathrm{p}<0.01\right)$, feeling of insecurity ( $t_{\mathrm{emp}}=5$ with $\left.\mathrm{p}<0.01\right)$, communication difficulties $\left(\mathrm{t}_{\mathrm{emp}}=6.4\right.$ with $\mathrm{p}<$ $0.01)$ and depression $\left(t_{\text {emp }}=2.8\right.$ at $\left.\mathrm{p}<0.01\right)$. Thus, as a result of mental deprivation, the need for security is not satisfied, which forces the adolescent to defend himself, showing aggression and hostility towards others or direct this aggression towards himself;

- the obtained data according to the methodology "Assessment of self-confidence" by T.P. Skripkina showed that in the group of adolescents from the experimental group, the level of trust is much lower than that of adolescents from the control group in terms of such indicators as: "trust in education" $\left(\mathrm{t}_{\mathrm{emp}}=2.8\right.$ at $\left.\mathrm{p}<0.01\right)$; "trust in relationships with friends" $\left(\mathrm{t}_{\text {emp }}=2.8\right.$ at $\left.\mathrm{p}<0.01\right)$; "self-confidence in the intellectual sphere" $\left(\mathrm{t}_{\mathrm{emp}}=3.4\right.$ at $\left.\mathrm{p}<0.01\right)$; "self-confidence in relationships with parents" ( $\mathrm{t}_{\mathrm{emp}}=2.9$ at $\left.\mathrm{p}<0.01\right)$;

- the results of the methodology of A. Bass and A. Darka "Diagnostics of indicators and forms of aggression" revealed statistically significant differences between the groups in terms of indicators of all forms of aggression: physical aggression ( $\mathrm{t}_{\mathrm{emp}}=2.8$ at $\mathrm{p}<0.01$ ), verbal aggression $\left(t_{e m p}=2.7\right.$ with $\left.p<0.01\right)$, indirect aggression $\left(t_{e m p}=3.0\right.$ with $p<0.01$ ), suspiciousness ( $\mathrm{t}_{\mathrm{emp}}=3.4$ with $\mathrm{p}<0.01$ ), touchiness ( $\mathrm{t}_{\mathrm{emp}}=2.6$ with $\mathrm{p}<0.01$ ), auto aggression $\left(t_{e m p}=3.1\right.$ at $\left.p<0.01\right)$. Using the data obtained, it can be assumed that the manifestation of aggression in a deprived adolescent is a consequence of a feeling of insecurity, which leads to the deprivation of trust and the development of destructive behavior;

- in adolescents from the experimental group, the scale "acceptance of others" is below normal ( $\mathrm{t}_{\mathrm{emp}}=5.1$ with $\left.\mathrm{p}<0.01\right)$ and "self-acceptance" is below normal ( $\mathrm{t}_{\mathrm{emp}}=4.1$ with $\mathrm{p}$ $<0.01$ ) (method "Acceptance of others" according to the Feuillet scale). The low level of selfacceptance and acceptance of other people in deprived adolescents is manifested in the difficulty of adapting to new conditions of activity, difficulty in establishing social contacts and trusting relationships;

- the results of the study of social adaptation, communication skills and communication control showed that adolescents with psychological security disorders show low adaptive abilities "low adaptation" ( $\mathrm{t}_{\mathrm{emp}}=7.3$ with $\left.\mathrm{p}<0.01\right)$; low communicative control ( $\left.\mathrm{t}_{\mathrm{emp}}=2.7\right)$; a reduced indicator of benevolence ( $\left.t_{\mathrm{emp}}=2.7\right)$.

The results obtained prove that trust in oneself and in the world is a basic factor influencing all components of the structure of a person's psychological security (affectivepersonal, cognitive, value-semantic and behavioral).

Based on the results of the empirical study and the author's model, a complex of psychocorrectional measures has been developed aimed at the formation of trusting relationships as the basis of psychological security of the personality of an adolescent who finds himself in a difficult life situation. The basis for approbation of the author's psychocorrectional program "I-value" was SPI SS "Volzhsky social rehabilitation center for minors" and SSPI SS "Volzhsky center for helping children who have remained without parental care".

The goal of the psychocorrectional program "I-value" is to optimize trusting relationships among adolescents, which has a positive effect on the formation of their psychological safety and provides constructive strategies for behavior in a difficult life situation.

When carrying out corrective measures, we focused on the following: creating conditions for confidential emotional communication, the formation of emotional and moral standards and models of adequate behavior, the consolidation of positive attitudes and value orientations through the inclusion of adolescents in interactive activities.

The psychocorrectional complex was based on classes that were divided into three cycles. 
The objectives of the first cycle were: relieving anxiety and depression. The second cycle of classes was aimed at solving problems related to the correction of negative social experience, the development of communication skills, release from aggressive behavior patterns, the formation of the ability to independently resolve conflicts. And finally, the tasks of the third cycle included: the formation of adolescents' self-worth attitude towards themselves, which significantly increases the level of self-confidence and forms a sense of security.

The structure of the program correlates with the developed model of the formation of trusting relationships as the basis for the psychological safety of a person and includes the following components:

1. The affective-personal component involves the formation of the adolescent's ability to feel and empathize with another person, to give emotional assessments of the process of trusting interaction, to feel his emotional background and the mood of others.

2 . The cognitive component presupposes the acquisition of knowledge about oneself, the world and social norms, the formation of an attitude towards self-knowledge, self-realization.

3. The behavioral component consists in the formation of practical skills in the adolescent and the ability to build safe strategies of protective behavior.

4. The value-semantic component presupposes the formation of positive attitudes in the perception of the surrounding social space and one's "I" based on the significance of the values of human existence.

Group and individual psychotherapy, body-oriented and art therapy, as well as sociopsychological training were used as the main form of psychocorrectional work. Correctional and developmental classes were conducted 2 times a week for 2-3 hours for 3 months. At the control stage of the study, the effectiveness of the developed psychocorrectional program for the formation of a sense of self-worth and trusting relationships in adolescents who found themselves in a difficult life situation was determined.

In order to identify the effectiveness of the developed program, we used control testing after classes and studied the significance of differences between the indicators of the first and second tests using the paired Wilcoxon t-test.

The values of $t_{\text {emp }}$ obtained according to the methods carried out, diagnosing the level of acceptance of others according to the Feuillet scale ( $t_{\text {emp }}=22$ with $\left.p \leq 0.01\right)$, the level of selfconfidence according to the method of T.P. Skripkina ( $t_{e m p}=19$ with $p \leq 0.01$ ), the level of interpersonal trust according to J. Rotter's method ( $\mathrm{t}_{\mathrm{emp}}=17$ with $\left.\mathrm{p} \leq 0.01\right)$ and the level of personal anxiety according to the Spielberg-Khanin method ( $t_{\mathrm{emp}}=23$ with $\left.\mathrm{p} \leq 0,01\right)$ fall into the zone of significance. Consequently, the developed technologies for the formation of trust and psychological security of a person have shown their effectiveness for the tasks set.

An analysis of the results after the formative experiment revealed a positive dynamics in the development of interpersonal and trusting relationships in adolescents brought up under conditions of mental deprivation before and after correction.

In the experimental group, after corrective measures were taken, the indicators of the level of interpersonal trust (J. Rotter's method) increased by $25 \%$, the level of self-confidence (T. P. Skripkina's method) increased by $37 \%$. The level of high personal anxiety in deprived adolescents decreased by $20 \%$, at the same time, the level of moderate anxiety increased, which indicates a positive trend towards a decrease in personal anxiety in adolescents. After the experiment, the level of acceptance of others increased by $22 \%$.

Thus, the conducted psychocorrectional program contributed to an increase in the level of confidence in oneself and in the world among adolescents who found themselves in a difficult life situation. After participating in the formative experiment, adolescents began to trust themselves more in solving educational problems, in the ability to build relationships with friends, they began to believe more in their intellectual abilities. 
Consequently, the developed techniques for the formation of trust and psychological security of a person, which were the author's model and a complex of psychocorrectional measures, are effective for building new adequate forms and models of behavior, attitudes towards trust in oneself and in the world, reducing personal anxiety and feelings of insecurity in adolescents in deprivation conditions.

\section{Discussion}

This study proposes an innovative approach that considers the problem of the formation of trusting relationships as the basis of psychological security of an adolescent's personality from a new point of view through the phenomenon of "trust-distrust" within the framework of deprivation concepts.

In recent years, foreign psychology has been actively investigating the problem of trust and trusting relationships. It should be noted that among the entire set of works, the authors distinguish three main areas within which research on trust is being conducted: 1) studies of the relationship between trust and the psychological health of a person; 2) studies of the relationship between trust and the level of development of interpersonal relations; 3) study of the role of trust in cooperation as a prerequisite for the successful work of the organization. We are interested in the studies devoted to the relationship between trust and the psychological health of a person, as well as studies of the relationship between trust and the psychological security of a person. The most famous, classic works of the first area were works by D.V. Winnicott, K. Rogers, K. Horney, E. Erickson. Almost all authors considered trust to be the most important condition for a healthy life of a person.

Despite the relative development of such phenomena as trust and psychological security of a person, we have studied this problem using the example of adolescents developing under conditions of deprivation. In our work, the problem of personal trust and psychological security is considered as an interdependent process. On the one hand, one of the conditions for the emergence of trust is the significance and safety of objects of the surrounding (primarily social) world; on the other hand, for the formation of psychological security, a person needs basic trust in himself and in the world.

The analysis of the conducted theoretical studies and the results of correctional work show that trust in oneself and in the world is the basic factor of the personality, affecting all components of the structure of psychological security of a person (affective-personal, cognitive, behavioral and value-semantic).

\section{Conclusions}

Comparative analysis of the obtained results of the empirical study of the experimental and control groups made it possible to confirm the reliability of the identified components of psychological security and the criteria of trust/distrust in the author's model.

The introduction of these techniques made it possible to form adequate attitudes towards trust in themselves and in the world, to reduce personal anxiety and aggressiveness in adolescents who find themselves in a difficult life situation.

Based on the foregoing, some generalizations can be made: adolescents who develop under conditions of deprivation have a low level of trust in the world and self-confidence. We called this phenomenon "trust deprivation", which manifests itself in a low level of social adaptation, an underestimated level of self-acceptance, as well as in the severity of aggressive reactions and high anxiety.

Not providing timely assistance to deprived adolescents who find themselves in a difficult life situation leads to profound personal deformations (high aggression, depression, cruelty, 
affective outbursts, conflicts), which often leads to inappropriate behavior, from which both the adolescent himself and people around him suffer. This necessitates the formation of trusting relationships in adolescents, including trust in oneself and in the world, as well as the study of the phenomenon of trust deprivation as a consequence of the influence of a difficult life situation and violation of the psychological security of the adolescent's personality.

For the full development of the personality of $\mathrm{n}$ adolescent, the need for psychological security must be satisfied. Failure to satisfy this basic need leads to deformation of the personality development. The use of the above techniques for the formation of trusting relationships will help to optimize the personal development of an adolescent, taking place in a difficult life situation.

\section{Acknowledgements}

The publication was carried out with the financial support of the Russian Foundation for Basic Research, project No. 19-013-00331 on the topic "Confidence in oneself and in the world as the basis of psychological security of adolescents in difficult life situations"

\section{References}

1. M.V. Danilova, L.V. Rykman, Psychological Science and Education 23(5), 40-50 (2018) DOI: https://doi.org/10.17759/pse.2018230505

2. A.V. Polina, E.V. Ovcharova, Educational bulletin "Consciousness" 21(9), 11-17 (2019) http://dx.doi.org/10.26787/nydha-2686-6846-2019-21-9-11-17

3. V.N. Oslon, Psychological Science and Education 21(1), 146-155 (2016) DOI: https://doi.org/10.17759/pse.2016210113

4. B. Bastecká, H. Boukalová, Psychology in Russia: State of the Art 13(1), 82-98 (2020) DOI: https://doi.org/10.11621/pir.2020.0108

5. T.P. Skripkina, The european proceedings of social \& behavioural sciences epsbs 651 657 (2019) DOI: https://doi.org/10.15405/epsbs.2019.07.85

6. A.V. Polina, E.V. Ovcharova, Eurasian Union of Scientists 10(67).10, 32-35 (2019) DOI: https://doi.org/10.31618/ESU.2413-9335.2019.10.67.408

7. P.A. Kislyakov, V.N. Feofanov, E.A. Shmeleva, O.A. Silaeva, Society of Russia: educational space, psychological structures and social 8, 85-98 (2017) DOI: https://doi.org/10.12731/2218-7405-2017-8-85-98

8. T.O. Archakova, A.N. Veraksa, O.Y. Zotova, E.B. Perelygina, Psychological Science and Education 22(6), 68-76 (2017) DOI: https://doi.org/10.17759/pse.2017220606

9. C. Ryff, B. Singer, Journal of Happiness Studies 9(1), 13-39 (2008) DOI: 10.1007/s10902-006-9019-0

10. T.K.A. Hunt, K.S. Slack, L.M. Berger, Child Abuse \& Neglect 67, 391-402 (2017) DOI: https://doi.org/10.1016/j.chiabu.2016.11.005

11. M.J. Gardner, H.J. Thomas, H.E. Erskine, Child Abuse \& Neglect 96 (2019) DOI: https://doi.org/10.1016/j.chiabu.2019.104082

12. J.R. McTavish, A. Gonzalez, N. Santesso et al., BMC Pediatr 20, 113 (2020) DOI: https://doi.org/10.1186/s12887-020-2015-4

13. J.M. Warmingham, F.A. Rogosch, D. Cicchetti, Child Abuse \& Neglect 102 (2020) https://doi.org/10.1016/j.chiabu.2020.104377 
14. J. Coleman, Child \& Family Social Work. Special Issue: Teenagers in Foster Care 24(3), 354-359 (2019) https://doi.org/10.1111/cfs.12605

15. J.I. Herzog, Ch. Schmahl, Front Psychiatry 9, 420 (2018) DOI: https://doi.org/10.3389/fpsyt.2018.00420

16. A.N. Almas, L.J. Papp, M.R. Woodbury, Ch.A. Nelson, Ch.H. Zeanah, N. Fox, Child Development 91(1), 96-109 (2018) DOI: https://doi.org/10.1111/cdev.13169

17. M.V. Ermolaeva, O.V. Smirnova, Psychological science and education 25(1), 51-62 (2020) DOI: https://doi.org/10.17759/pse.2020250105

18. L.A. Golovey, M.V. Danilova, Izvestiya of Saratov University. New series. Series: Educational Acmeology. Developmental Psychology 8(1), 38-45 (2019) DOI: https://doi.org/10.18500/2304-9790-2019-8-1-38-45

19. K. Hawley, University of St Andrews 48(1), 1-20 (2014) DOI: https://doi.org/10.1111/nous. 12000

20. Ya.S. Suntsova, Vestnik of the Udmurt University. Series Psychology 30(1), 33-47 (2020) DOI: https://doi.org/10.35634/2412-9550-2020-30-1-33-47

21. O.V. Runets, Social psychology and society 6(4), 170-182 (2015) DOI: http://dx.doi.org/10.17759/sps.2015060413

22. Ts.A. Shamlikashvili, S.V. Kharitonov, D.N. Pchelintseva, V.P. Grafsky, Psychology and Law 8(2), 138-151 (2018) DOI: https://doi.org/10.17759/psylaw.2018080211

23. T.D. Dubovitskaya, G.F. Tulitbaeva, A.V. Shashkov, Vestnik of the Peoples' Friendship University of Russia. Series: Psychology and Pedagogy 14(2), 213-225 (2017) DOI: http://dx.doi.org/10.22363/2313-1683-2017-14-2-213-225

24. L.S. Evert, T.V. Potupchik, N.Yu. Grishkevich, Yu.R. Akhmeldinova, Review of psychiatry and medical psychology 4, 75-82 (2018) DOI: https://doi.org/10.31363/23137053-2018-4-75-82

25. I.V. Gorodetskaya, N.Yu. Konevalova, V.G. Zakharevich, Vestnik of VSMU 5 (2019) DOI: https://doi.org/10.22263/2312-4156.2019.5.120

26. T.G. Mukhina, I.G. Lukichev, A.Yu. Sutugin, Society: sociology, psychology, pedagogy 6 (2017) https://doi.org/10.24158/spp.2017.6.7 